\title{
Identifying the Wasted Spaces within Hospital Buildings in Pakistan
}

\author{
JAVERIA MANZOOR SHAIKH*, KHAN MUHAMMAD BROHI**, AND SABEEN QURESHI***
}

RECEIVED ON 06.02.2018 ACCEPTED ON 30.10.2018

ABSTRACT

The built environment of hospital buildings are generally not accepted to be pleasant. In the design of healthcare facility, it is quite important that its design, spatial arrangement and areal distribution must respond to curative needs of people so as the outcome emerge in the form of healing environment in the physical spaces.This kind of healing environment is quite adequately available in the developed countries of the global north. However; in developing countries of the global south like Pakistan, the healing environment in healthcare facilities is neither documented nor evident in any available published literature. Whereas, it needs to be well documented and analyzed. Thus, this study aims to identify the healing environment in two selected hospital buildings in Pakistan that is ICP (Peshawar Institute of Cardiology) and FCP (FC Hospital Peshawar) by determining the percentage of wasted spaces within the building. The selected buildings are analyzed from the following aspects; circulation pattern in the hospital, accessibility, connectivity and barrier free movement within buildings, along with the walkability status of over stressed staff inside the hospital building while navigating, functionality of the schematic designs, the problem of the users concerning repetitiveness in their circulation pattern and the way to increase the efficiency of spaces, their spread and flow in the hospital building. In general, three key factors were investigated in this study, therefore, design determinents, areal distribution and adequate spatial organization. In this regard, total eight design determinants were investigated, i.e. entry, parking, waiting area, connectivity, visibility, walkability, accessibility, and way finding. Study approached the spatial simulation method therefore $3 \mathrm{M}$ analysis which is a Japanese model referred as Muda (waste), Muri (over burden), Mura (unevenness) based on the Kaizen theory for eliminating wasted spaces from Hospital buildings. Based on the findings and through the approached tools, the waste spaces within the hospital buildings were removed up to $40 \%$.

Key Words: Wasted spaces, Spatial organization, Kaizen theory.

\section{INTRODUCTION}

1 $\mathrm{t}$ the time of partition from India, Pakistan's state of public health was very poor and faced immense difficulties to procure trained personnel as well as material for the management and development of hospitals. Before 1947, due to the lack of efficient workers, the medical institutions were illequipped and ill-staffed, poorly designed and not up to the mark to meet health emergencies. After Partition the

\footnotetext{
Authors E-Mail: (javeria.shaikh@uac.edu.pk, khan.brohi@faculty.muet.edu.pk, sabeen.qureshi@faculty.muet.edu.pk) * Department of Architecture, University of Arts \& Culture, Jamshoro, Pakistan.

** Institute of Environmental Engineering \& Management, Mehran university of Engineering \& Technology, Jamshoro, Pakistan.

*** Department of Architecture, Mehran university of Engineering \& Technology, Jamshoro, Pakistan.
}

This is an open access article published by Mehran University Research Journal of Engineering and Technology, Jamshoro under the CC by 4.0 International License. 
government has made little effort in improving the hospital facilities and build more hospitals. In Pakistan, the total number of healthcare services, i.e. community health centers, polyclinics, primary, secondary and tertiary hospitalsare only 8306 . From among them 1356 are primary scale hospitals, 1255 are secondary scale hospitals, 394 are tertiary scale hospitals and the remaining are community health centers and polyclinics. Pakistan has four main provinces, i.e. Punjab, Sindh, Balochistan and KPK (Khyber Pakhtunkhwa) [1]. This country lacks documented record of hospital plans and design, thus the first issue is to collect data about the hospital buildings and selection of samples. In this regard a small scale reconnaissance survey of 02 hospital buildings was conducted by the author during the year 2017. The hospital buildings that were selected from KPK province were 02 in number which were of secondary and tertiary scale which were studied with the lens of healing environments. The survey found out that the hospitals of Pakistan have a very small percentage of healing places, that is to say, only $11 \%$ of the places were healing spaces.

So this research proposes to improve the design of hospital building with the help of a comprehensive framework for the healing environment indicators [2]. The aim of this research is to visualize and analyze the status of healing environment in selected hospital buildings within Pakistan. Various tools and techniques were explored in this regard and case studies were conducted in Pakistan to evaluate the hospitals to study the factors to be considered for the healing environment within the hospitals from early stages of design to final product. Thus the total of two case study of hospital projects are mentioned in this research i.e. ICP and FC Hospital FCP. These case studies were analysed in three key factors therefore, Design Determinants, Areal Distribution modeling and Spatial Organization by using 3M Analysis tool based on Kaizen theory to identify the waste spaces with in hospital building.

The professional contributions of proposed research are the development of practical guidelines for professionals in terms of local design determinants and spatial organization of hospital buildings [7-9]. The development of possible local standards for areal distribution of hospital buildings in Pakistan would lead to development of professional regulations and bylaws that may be pertinently applicable for local context.

\subsection{Literature Review}

The literature review consists of eight main aspects. It begins by understanding the concept of healing environment and defining hospital buildings in Pakistan. Then three aspects of ensuring healing environment in hospital buildings were studied [10]. These included the concepts of design determinants, spatial organization and areal distribution. The other three concepts explored through literature review were the analytical tools to ensure the healing environment and were used in various industrial and technological contexts. These include $3 \mathrm{~m}$ analysis tools of Muda, Muri, Mura. The indoor navigational localization application leveraging and its comparison with the sensing capabilities of the smart phones. On one hand the application proposed is to be implemented in smart phones delivering an accuracy of up to 1.5 meters. On the other hand, creating universally designed places is integral to rehabilitation. Approaches to UD (Universal Design) focus, primarily, on the development and application of technologies and techniques to ensure environments are accessible. UD appears to be a technology-led movement [4]. Before UD is used as the basis for rehabilitation, more research is required to identify the values shaping its principles, to evaluate how far they represent the most coherent approach to creating an accessible built environment.

Mehran University Research Journal of Engineering \& Technology, Volume 38, No. 3, July, 2019 [p-ISSN: 0254-7821, e-ISSN: 2413-7219] 
There are a number of great attempts to develop an indoor navigation that provide the most optimal path and guidance. Finding a way in large buildings can be a challenging task [5]. Specifically, literature review is rather limited in the domain as there are more papers about determining optimum spaces in buildings. In this research the literature is also added for universal design, which must take into account of wheelchair persons, movement of large furniture (beds, cupboards, equipment, etc.) and other interior equipment specifically for ICU [6-8]. The issues discussed in those papers are also valid to the authors' hospital cases. In order to represent the real situation to a maximum extent, a representation of the whole room as one single indivisible object is not enough as such representation is very abstract and this could make the navigation difficult and may result in inefficient route planning. In order to provide a smooth navigation path, the presence of humans within the indoor environment and the natural movement of individuals should be taken into consideration. Sisi [8-9] discussed a two-step indoor space subdivision for indoor navigation is described. Firstly, the indoor space is subdivided into navigable and non-navigable areas considering human perceptions of the environment and human behavior. Secondly, the navigable space is subdivided applying a constrained Delaunay triangulation. Finally, the guidelines for generation of the navigation network and verification of the proposed model are presented here in this research.

The literature presents a conceptual foundation of the description of interiors of buildings [10]. This framework concentrates specifically on physical and conceptual subdivisions of indoor space, which supports indoor localization and navigation. Considering user and environmental factors into account, it can be used for flexible context aware path-planning in any indoor environment. Although wayfinding and orientation in complex buildings is an important criterion for environmental behavior, research on the subject remains limited and the issue is not considered sufficiently during the design process. The article [11-12] examines the factors that affect wayfinding behavior of individuals in a shopping mall and explains how their behaviors are influenced by factors such as building configuration, visual accessibility, circulation systems, and signage.

\subsubsection{Definition of Healing Environment}

Healing environment concept emerged in mid-19th century which indicates treatment of the environment to be curative [7]. In 1960's, the concept of healing environments got scientific underpinning through Evidence-Based Design. By the mid-1980s Roger Ulrich made first evidence based research on healing environment by identification of the effect of built environment on patients. This has instigated the researchers to further identify the effects of natural and built environment on patient's healing. Many architectural researches conducted in this regard with the application of different methodologies and developed an academic structure and knowledge base as intended in this research. Currently there is a collective understanding that a healing environment is beneficial for patients and for healthcare staff. Healing principles [9] and evidence based design [12] are applied to augment and optimize the outcomes of care quality. The user's instinctive healing ability is developed by incorporating specified aspects of architectural design in healing spaces [4]. As these theories on healing environment were applied at international level and widely used within the developed world of the global north. Logically, it requires that, such concepts may be tested in developing countries of global south or new such theories may be developed. In this regard the context of Pakistan is proposed to be a significant case study where these concepts and theories may be applied and tested [13-15]. 


\subsubsection{Definition of Hospital Buildings in Pakistan}

There is no single definition to describe the hospital buildings in Pakistan because the nature and scale of such structures vary to greater extent from one room polyclinic to large scale tertiary level hospitals [21]. Therefore, this research describes about the distinctiveness of healthcare innovation and apply concept of synergy of healing spaces in architecture of hospitals in Pakistan. The synergism concept is driven from the emerging precise state-of-the-art technology, as a source of an effective design for stimulation of healing for the individuals who is utilizing the healthcare setting [16]. This concept needs to be applied in the context of Pakistan.

\subsubsection{Muda}

Muda (Japanese for waste) that includes seven forms of waste: transportation, waiting, overproduction, inventory, movement, extra processing, and defects. Muda also means the basic waste at the workplace. There are various attributes of the concept of waste such as those factors that do not contribute to the processes going on in any hospital building [22]. Various kinds of wastes generated in a hospital building in terms of wasted spaces as well as wasted efforts of staff and other employees.

Muda is any activity or process that does not add value; a physical waste of your time, resources and ultimately your money. These wastes were categorized by TaiichiOhno within the Toyota production system. Many "lean" initiatives fail to see past the elimination of Muda and believe that the point of Lean is to just eliminate waste. This leads to implementations that initially appear to save money but quickly fall apart and revert as problems such as customer demand fluctuations and supplier problems occur.

\subsubsection{Muri}

Muri is waste caused by overstressing people, equipment, or systems and this concept was developed as a total quality model for hospital buildings [18-19]. The concept of Muri is like taking heavy mental or physical burden by workers on production sites. Similarly, for machinery it means excess workloads to equipment more than its normal capability. In hospital buildings this Muri is quite evident as the doctors, staff and nurses usually remained in excess workload more than their normal capability which cause issues that needs to be resolved.

Muri is to cause overburden, which mean giving unnecessary stress to employees and processes. This is caused by Mura and a host of other failures in a system such as lack of training, unclear or no defined ways of working, the wrong tools, and ill thought out measures of performance again Mura causes Muda, the seven wastes are symptoms of our failure to tackle Mura and Muri within the processes not the root cause.

\subsubsection{Mura}

Mura is waste due to unevenness or variation [13]. Lean in healthcare refers to wastage which could be eradicated by application of standardization in design. The concept of Mura is an irregularity and a temporary fluctuation in the total volume or parts of a facility or workers. Similar situation is also evident in the hospital buildings that there occurs an irregularity in the form and functions due to some temporary situation and that affect the facility's or people's performance [15]. Mura is the waste of unevenness or inconsistency, but what does this mean and how does it affect us. Mura creates many of the seven wastes that we observe, Mura drives Muda. By failing to smoothen out our demand we put unfair demands on our processes and people and cause the

Mehran University Research Journal of Engineering \& Technology, Volume 38, No. 3, July, 2019 [p-ISSN: 0254-7821, e-ISSN: 2413-7219] 
creation of inventory and other wastes. One obvious example is production processes where the manager is measured on monthly output, the department rushes like mad in the final week of the month to meet targets, using up components and producing parts not actually required.

\subsubsection{Summary}

The concepts of Muda, Muri and Mura suggests to remove the wasted efforts from hospital buildings and initiate value added works that may enhance the utility and functionality of hospital building and its people [23]. Similarly, an evident fact of hospitals is the overburdened spaces with extra furniture and fixtures and overburdened people with excessive workload due to emergency nature of hospital function and with high volume of patients and their caregivers. This creates unevenness in the spatial structure of hospital buildings and the irregularity, patchiness and roughness in the behavior of staff in the hospital buildings due to over stressed workload. This needs to be removed to achieve a wastage free or mistake proofing from their daily routine. Intensive literature review suggested that the wastage of space Muda, unevenness in planning Muri and variation eradication Mura can be achieved by space syntax usage.

\section{METHODOLOGY}

Both qualitative (analyzed through software simulation by rating within a given range between 1-5 with 1 representing as the worst and 5 representing as the best.) and quantitative (assessed on planning and architectural drawings) research approaches has been employed in this research based on subjective assessment with the help of interviews taken from hospital users, staff, nurses, doctors and healthcare professionals, facility managers, and architects (a public opinion) was documented for further analysis regarding their perception of different spaces within the hospital.

\subsection{Research Methods}

For the objective or actual assessment of hospital plans, visibility graph and axial line application in space syntax software has been used. The method adopted for this research includes literature review of the key concepts of healing environment and its application in hospital buildings [16-17]. In order to define the concept of hospital buildings in Pakistan a detailed survey of hospital buildings was carried out to find their types and characteristics. The information was collected from various geographical regions of Pakistan and from professional institutions and relevant experts in the field.

Total eight design determinants were investigated i.e. entry, parking, waiting area, connectivity, visibility, walkability, accessibility, and way finding [18]. With regard to spatial organization, the characteristics of individual space, site allocation plan and typology of circulation was especially examined [24-25]. Concerning areal distribution, the total spatial sizes, standards and areas allocated to individual rooms and spaces were studied of selected hospital buildings. These three key factors therefore design determinants, spatial organization and the areal distribution were analyzed and examined through the data obtained from interviews and $3 \mathrm{M}$ analyses tool which further eradicated the waste spaces in Space Syntax application.

\subsection{Case Analysis}

Two case studies of secondary and tertiary hospitals from Peshawar were carried out during this research and earlier mentioned tools were applied to them. These two cases given here are the acute care or secondary care hospital

Mehran University Research Journal of Engineering \& Technology, Volume 38, No. 3, July, 2019 [p-ISSN: 0254-7821, e-ISSN: 2413-7219] 
buildings within Pakistan. The reason for selection of these acute care or secondary care hospital cases is twofold. First the secondary hospital is quite primitive in nature and may be quite smaller in scale for this paper. Second, the tertiary care hospital is of very large scale with university and community functions attached to it which make them beneficial for incorporation in this research.

These hospitals; features evaluated of the selected hospitals is analyzed through three analytical tools therefore Muda-Mura-Muri in which wasted spaces were eradicated with the application of Space Syntax [20]; Stress from staff was eradicated by applying axial line for barrier free accessibility and way finding; whereas, the eradication of variety in spaces that creates a puzzlement was also carried out through visibility graph.

\subsubsection{Descriptions of Analysis}

The process of analysis began with the establishment of guidelines on TQM (Total Quality Management) for the design and development of healthier and happier hospitals fit for Peshawar [4]. In these acute care hospitals, the standard for healing design is achieved by providing mechanism for efficiency and productivity as well as healthier building design. It is tried to achieve more efficient and new vision where client's point of view was the prime significant element to reduce the size of building so that corridors become direct and barrier free with maximum efficiency and minimum wastage space [5]. Through interviews with hospital users, staff, nurses, doctors and healthcare professionals, facility managers, and architects a public opinion was documented for further analysis [6]. These include 3M analysis (i.e. Muda, Mura, and Muri), with these analyses a concept of zero defects in hospital buildings was introduced for future hospital development and to improve the healing environment.

\subsubsection{Case-1: Institute of Cardiology Peshawar Hospital}

ICP is a seven story hospital building which has a lot to offer to the patients and visitors. The building is located on the main road and the ground in between the hospital and the main road helps to minimize the traffic noise and keep the environment protected and sound. Pharmacy is also on the ground floor, at the central junction, beside the ramps and elevators. The central point provides various linkages to the wards, emergency department, heart care and OPD. The Inpatient department for Peshawar Institute of Cardiology consists of app 800 beds. The bed distribution for each ward is half of the male and half of the female, therefore 24 male and 24 female and one side room for male and one for female. The location of the washrooms is at the entrance of each ward. There are 3 Medical wards, 3 Surgical, 3 for Gynecology 1 ENT, 1 Eye, 1 Gastro, 1 Pulmonary, 3 Peads, 1 Nursery, 1 Neurology 1 Urology, 1 Cardiology, 1 Oncology, 1 Endocrinology, 1 Dermatology, 1 Cyeatry, 1 Orthopedics and 1 Burn unit of 25 beds. The Labor room is near the nursery, which accommodates 15 incubators. All the spaces in hospital are linked by, the well illuminated natural lighted corridors. The ducts running through the building are clearly visible and thus distracting the visitors. The wards are placed separately in the master plan and away from the main building which provides a quiet environment. The problem which sometimes arises in the peak hours is the "Time" it takes to transfer the patient to the OT's in the inpatient department.

The first step in the analysis of spatial organization of ICP is to make AutoCAD drawings of Hospital building. Fig. 1 depicts the typical floor plans of the hospital building with division of spaces. These plans were drawn to identify the existing condition of the Hospital building.

The second step in the analysis of spatial organization of ICP is Muda with the application of Space Syntax software to identify space utilization. Fig. 2 depicts the typical floor plans of the ICP hospital building with division of spaces.

Mehran University Research Journal of Engineering \& Technology, Volume 38, No. 3, July, 2019 [p-ISSN: 0254-7821, e-ISSN: 2413-7219] 
These plans were drawn to identify the most used spaces, semi used spaces and less used spaces within the Hospital building. Three different colors were used in the space syntax diagram. Here red color identifies the most used spaces, orange shows the semi used spaces and blue color depicts the less used spaces in the building.
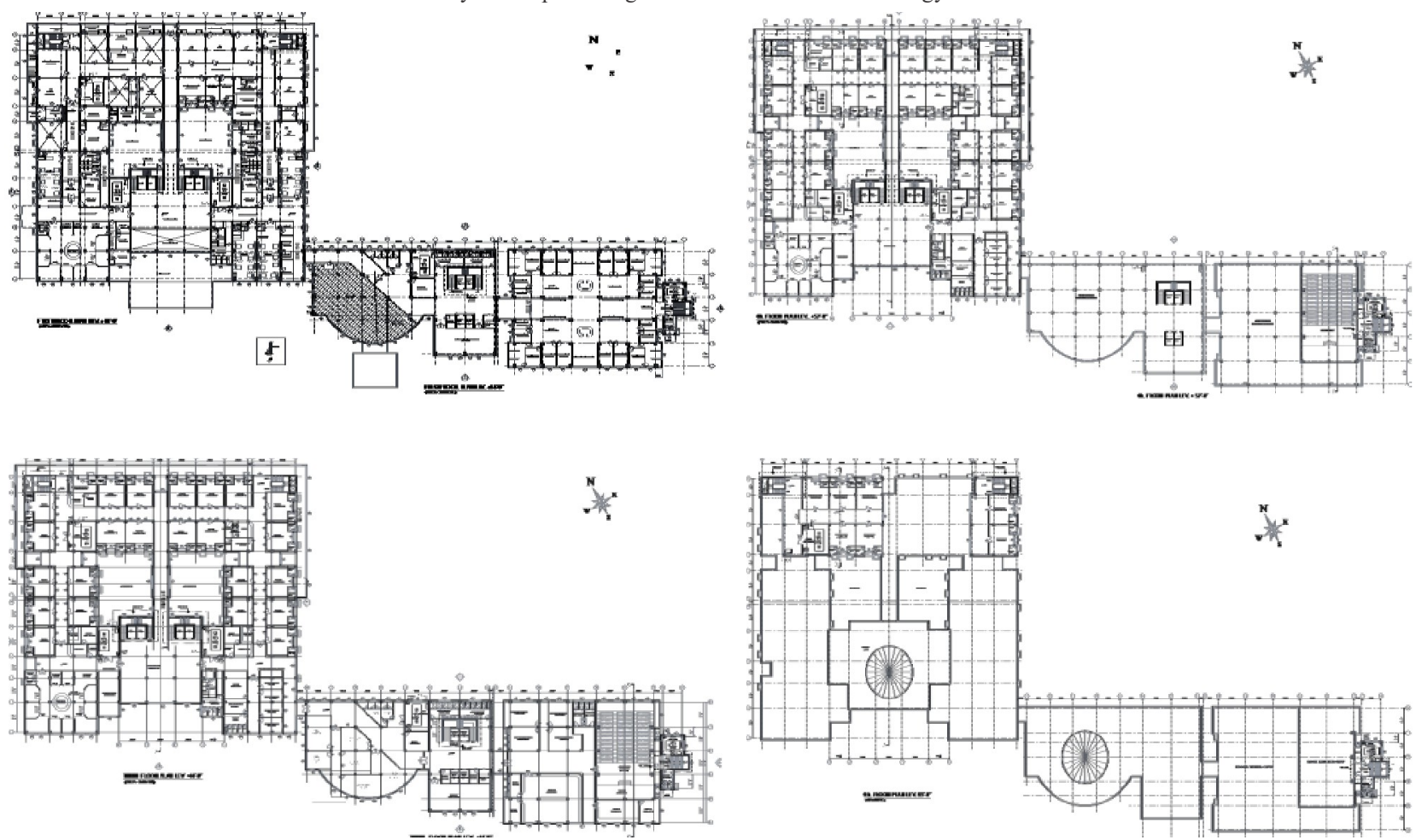

FIG. 1. PLANS OF HOSPITAL DEVELOPED WITH THE APPLICATION OF AUTOCAD

The Analysis of Spatial Organization Institute of Cardiology Peshawar
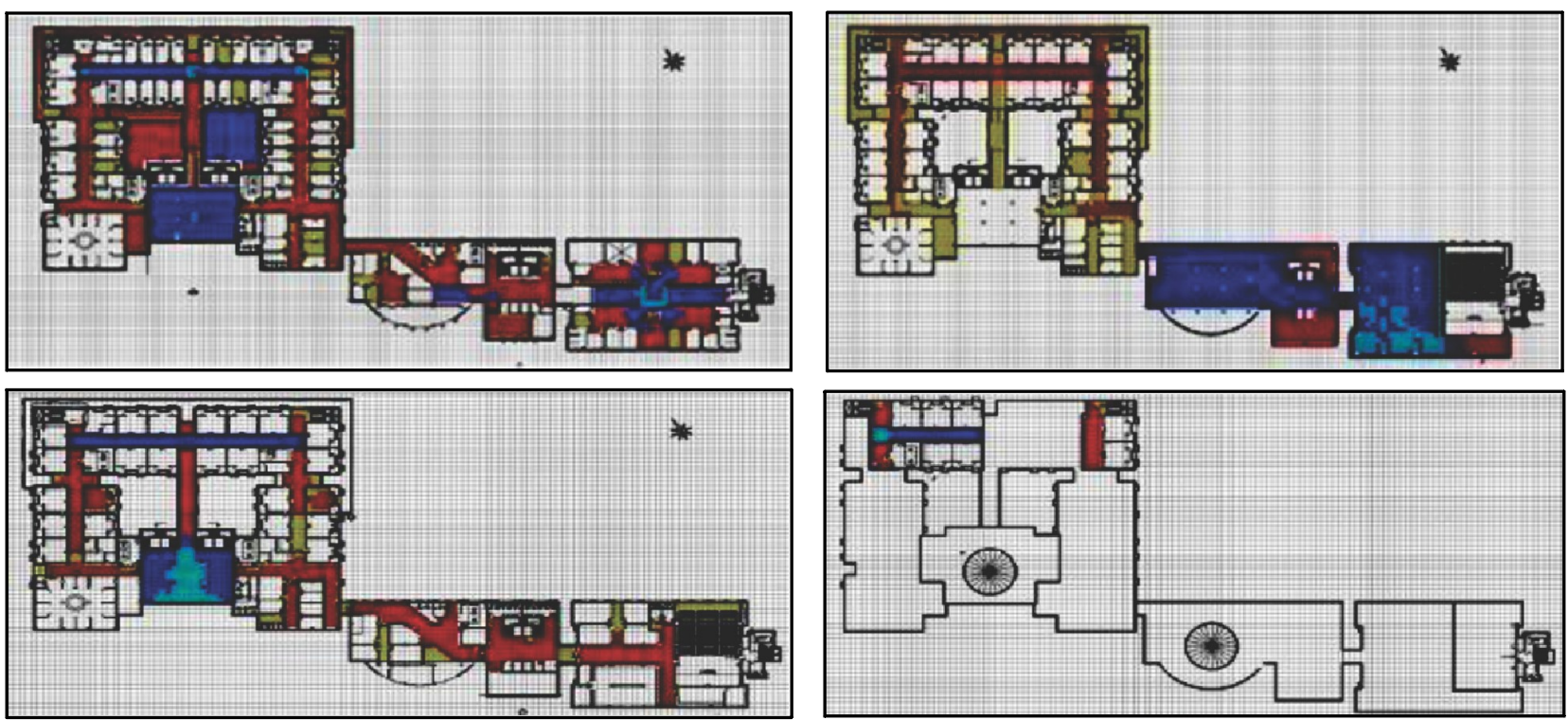

FIG. 2. MUDA WITH THE APPLICATION OF SPACE SYNTAX

Mehran University Research Journal of Engineering \& Technology, Volume 38, No. 3, July, 2019 [p-ISSN: 0254-7821, e-ISSN: 2413-7219] 
The third step in the analysis of spatial organization of ICP is Muri with the application of Axial Lines on the floor plans of the hospital to identify the circulation pattern and accessibility or barrier free movement within buildings. Fig. 3 depicts the typical floor plans of the ICP hospital building with axial lines depicting the circulation pattern and association between different spaces and their functions. The axial lines on floor plan are marked in red color. These axial lines are basically the connectivity lines which were also drawn to identify the walkability status of over stressed staff within the Hospital building.

The fourth step in the analysis of spatial organization of ICP is Mura with the application of Variation on the floor plans of the hospital to identify the functionality and circulation pattern for accessibility or barrier free movement within buildings. Fig. 4 depicts the typical floor plans of the ICP hospital building with Variation diagram depicting the circulation pattern of different people (i.e. users of the hospital) between various spaces. The spaces are drawn with rectangular and circular shapes whereas circulation is marked with arrows. These variation diagrams are basically drawn to show the schematic designs and solve the problem of the users concerning repetitiveness in their circulation pattern and increase their efficiency in the walkability and reduce the stress staff within the Hospital building.

The fifth step in the analysis of spatial organization of ICP is to take the feedback and opinion of the concerned people and users of the hospital building. A total 25 people were consulted and the earlier analysis done on MudaMura-Muri was shared with them. The selection of respondents was quite specific as the relevant respondents were indentified with support of International Red Cross. The group of respondents were from staff members, nurses, doctors and other healthcare professionals such as facility managers, and architects of the hospital.

Table 1 depicts the tabulation of the feedback and responses by the people interviewed. A grading on the scale of 1 as worst to 5 as best was taken from them on all

The Analysis of Spatial Organization Institute of Cardiology Peshawar
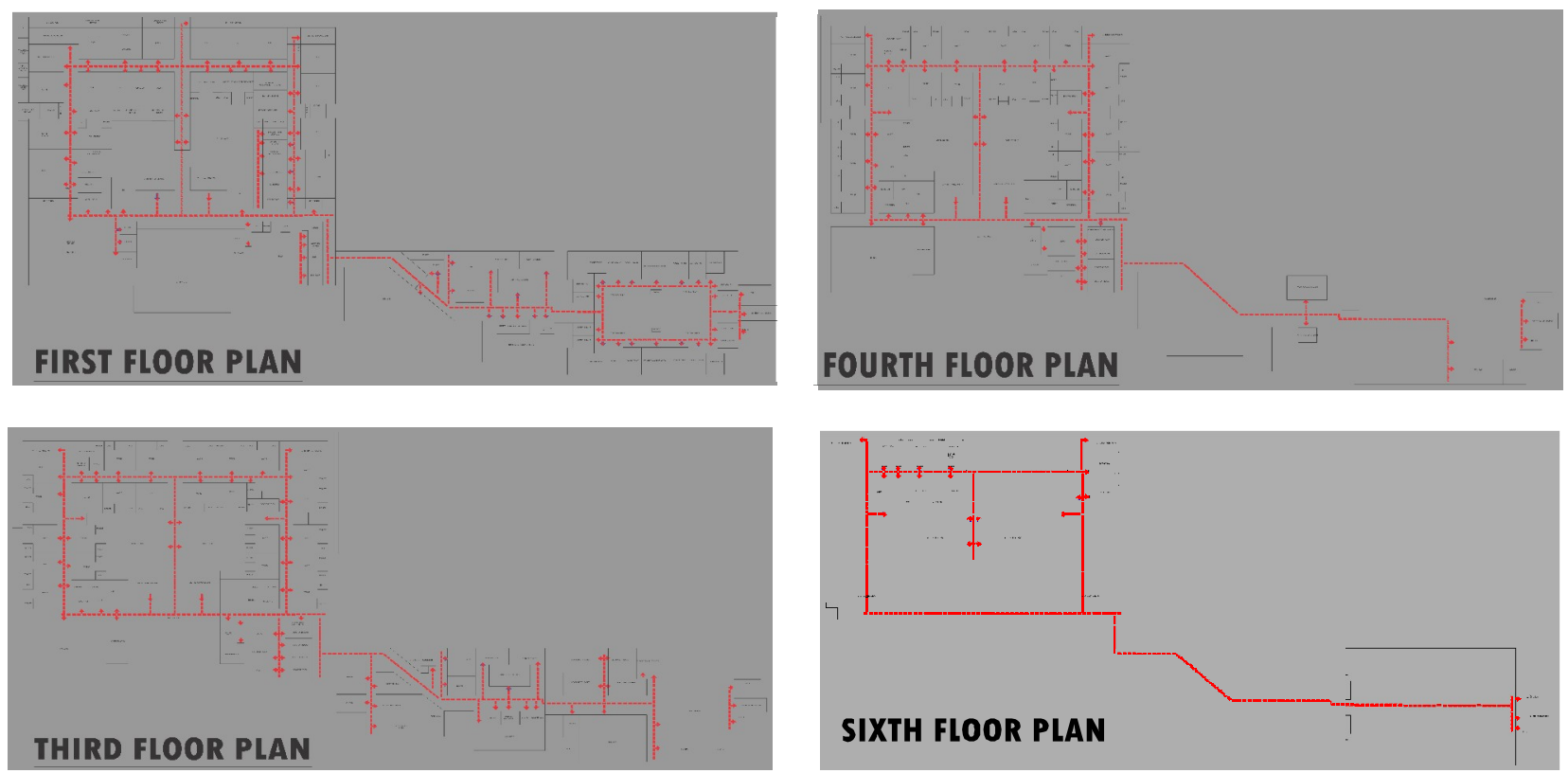

FIG. 3. MURI WITH THE APPLICATION ON AXIAL LINE

Mehran University Research Journal of Engineering \& Technology, Volume 38, No. 3, July, 2019 [p-ISSN: 0254-7821, e-ISSN: 2413-7219] 
three variables of Muda- Mura-Muri and their compound rating is depicted in Table 1.

The different aspects and issues on which the feedback of respondents were taken includes the division of spaces, space utilization, association between different spaces and their functions, most used spaces, semi used spaces and less used spaces. The analysis of spatial organization of ICP through respondent's interviews and grading portrays that it has quite less wastage spaces. The hospital is designed in such a way that it has very efficient circulation and connectivity within each department and quite minimum time is wasted in the mobility of the people and equipment.

The Analysis of Spatial Organization Institute of Cardiology Peshawar

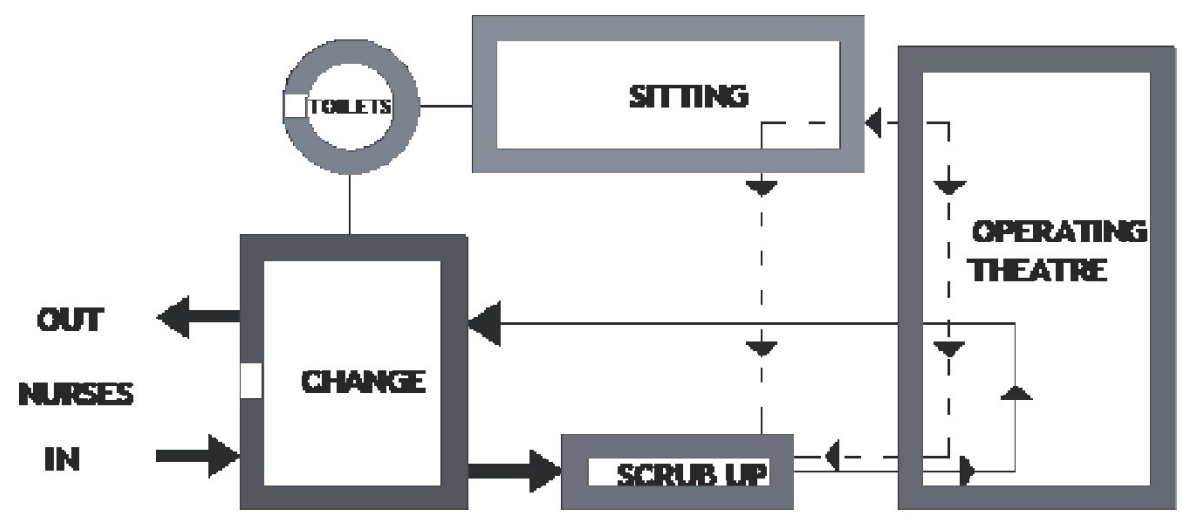

SURGEONS ANESTHETIST MAIN CIRCULATION

\section{PATIENT CIRCULATION DIAGRAM}

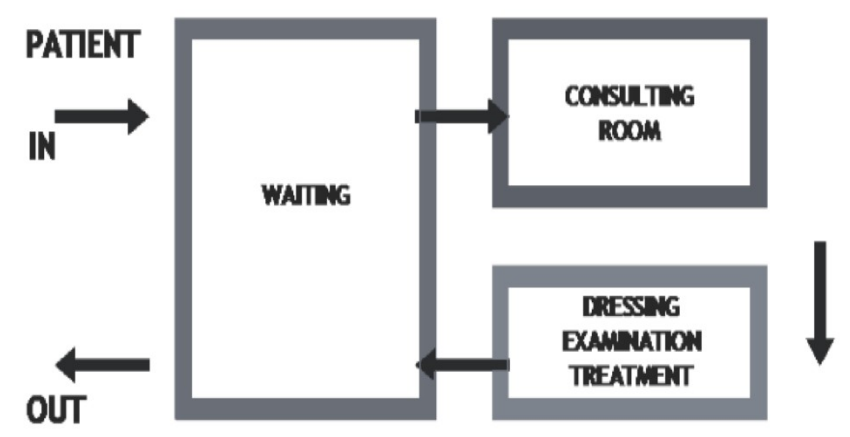

FIG. 4 MURA WITH THE APPLICATION OF VARIATION

TABLE 1. STATISTICAL ANALYSIS OF SPATIAL ORGANIZATION OF ICP

\begin{tabular}{|c|c|c|c|}
\hline \multirow{2}{*}{ Institute of Cardiology of Peshawar } & \multicolumn{3}{|c|}{ Spatial Organization } \\
\cline { 2 - 4 } & Muda & Mura & Muri \\
\hline Visibility Graph & 4 & 5 & 4 \\
\hline Space Syntax & 5 & 4 & 5 \\
\hline Axial Line & 5 & 4 & 5 \\
\hline
\end{tabular}

Mehran University Research Journal of Engineering \& Technology, Volume 38, No. 3, July, 2019 [p-ISSN: 0254-7821, e-ISSN: 2413-7219] 
Fig. 5 depicts the application of statistical analysis of spatial organization of ICP in which visibility analysis depicted through axial line. The axial line shows the efficiency of ICP hospital by linking the Muda-MuraMuri, as of 5, 4, and 3 from which it can be inferred that, a positive relationship is quite evident in the spatial organization of ICP hospital. It is because the axial line is inclined downwards from Muda to Mura and to Muri.

It may also be interpreted that since Muda is directly proportionate to Visibility and Mura is inversely proportionate to Axial line which means maximum visibility minimizes stress. Similarly, Muri is directly proportionate to Space syntax. In this case standardization adds to appropriate circulation and variation confuses the staff and visitors. With this analysis appropriate recommendations can be proposed for the improvements in spatial organization of Hospital Building.

It could be summarized that Mura is inversely proportionate to Axial Line, i.e. Mura $\alpha$ Axial Line ${ }^{-1}$. This is represented by orientation and corridor which shows $(++)$ relationship that is highly positive.

\subsubsection{Case-2: Frontier Corp Peshawar Hospital}

Health is a state of physical, mental and social well-being and not merely the absence of disease or infirmity. KPK is a province in Pakistan where mortality rate is high compared to the other provinces. FCP Hospital is working for the benefit of patients suffering from disease. The hospital building is divided into two specific portion i.e. in-patients and out-patients. The wards are placed separately in the master plan and located far from the main building which provides a quiet environment. The surgical beds are located near to the surgery in order to provide an easy access to surgery. The private wing has four floors, each connected to the main hospital with a corridor on each level. The second floor of hospital accommodates the Administration. The Inpatient department for FCP consists of 800 beds. Additionally, there are OPD's such as Peads, Speech therapy, Neurosurgery, Antenatal care and Gynecology. Also, there is a medicine store along with laboratories of Hematology, Histopathology, and Microbiology lab.

The Ancillary services include Pharmacy, Laboratory, Imaging, Transport, Housekeeping, Kitchen and Bio-

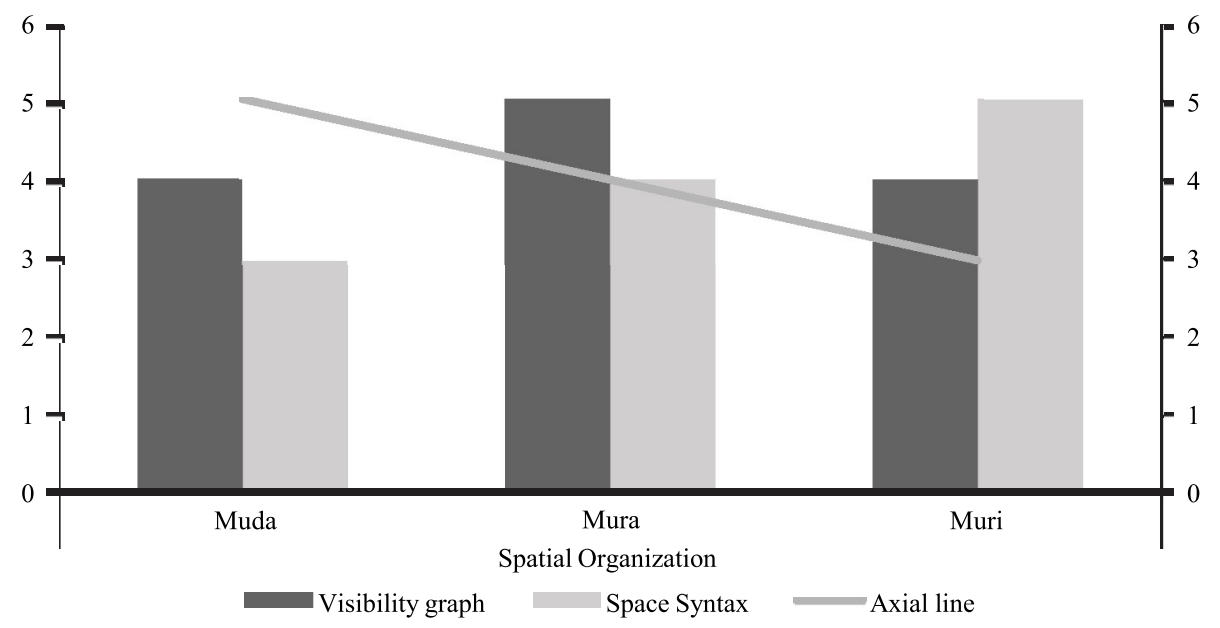

FIG. 5. STATISTICAL ANALYSIS OF SPATIAL ORGANIZATION OF ICP WITH THE APPLICATION OF VISIBILITY GRAPH, SPACE SYNTAX AND AXIAL

Mehran University Research Journal of Engineering \& Technology, Volume 38, No. 3, July, 2019 [p-ISSN: 0254-7821, e-ISSN: 2413-7219] 
medical. On the other hand, Specialized areas includes Emergency equipment, Emergency drug cart, Dirty utilities storage, Clean utilities storage, Washroom, Procedure room, Unit support zone, Administrative functions, Multipurpose conference room, Staff support room, Oncall room, Staffs lounge and Lockers. Family support zone includes Family lounge, Signage and way-finding, Environmental considerations, Consultation rooms, Meditation spaces, Family sleep rooms, Family nourishment.

The horizontal organization to the services area is through the corridor, while the vertical configuration connected by elevator shaft. It is clear that the whole complex is laid out on a hospital area which is stacked one over each other. In order to minimize the noise from the road, the wards are located on the upper floors. Because vertical circulation is very comfortable as it has easy access to the necessary service area of the main hospital.

The first step in the analysis of spatial organization of FCP is to make AutoCAD drawings of the Hospital building. Fig. 6 depicts the typical floor plans of the hospital building with division of spaces. These plans were drawn to identify the existing space distribution within the Hospital building. The second step in the analysis of spatial organization of FCP Hospital is Muda with the application of Space Syntax software to identify space utilization.

The Analysis of Spatial Organization in FCP Hospital
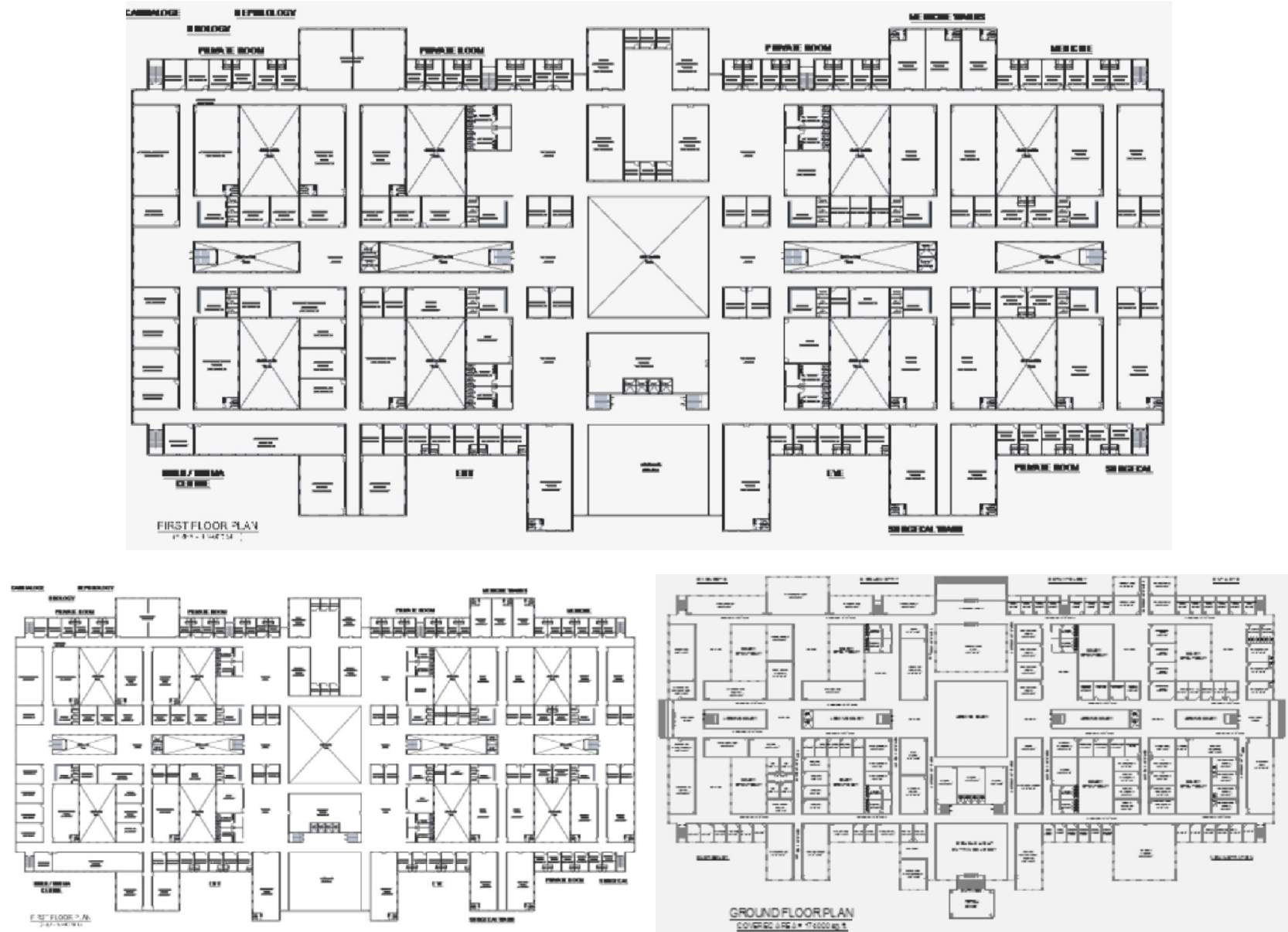

FIG. 6. PLANS OF HOSPITAL DEVELOPED WITH THE APPLICATION OF AUTOCAD 
Fig. 7 depicts two different floor plans of the FCP hospital building with division of spaces. These plans were drawn to conduct space syntax analysis and identify the most used spaces, semi used spaces and less used spaces within the Hospital building.

The space syntax diagram depicted here has been color coded. Here red colour identifies the most used spaces, yellow shows the semi used spaces and purple colour depicts the less used spaces in the building. The grey colour considered as the primary corridor in the building and blue as secondary corridor. The space syntax analysis depicts the connectivity evident in the FCP hospital and building is quite good in this respect.
The second space syntax image depicts the relationships between the solid and void or the relationship of built space and un-built space. The building has open to sky spaces which shows a character of healing environment. As Ulrich explains that open to sky space is a healing space which provides sunlight and air inside the building. Since FCP hospital provides the spaces open to the sky, it allowed the natural light and air inside the building which is healthy and heating within the hospital environment [11].

The third step in the analysis of spatial organization of FCP is MURI with the application of Axial Lines on the floor plans of the hospital to identify the breathing pockets and open to sky healing spaces within buildings. Through

The Analysis of Spatial Organization in FCP Hospital
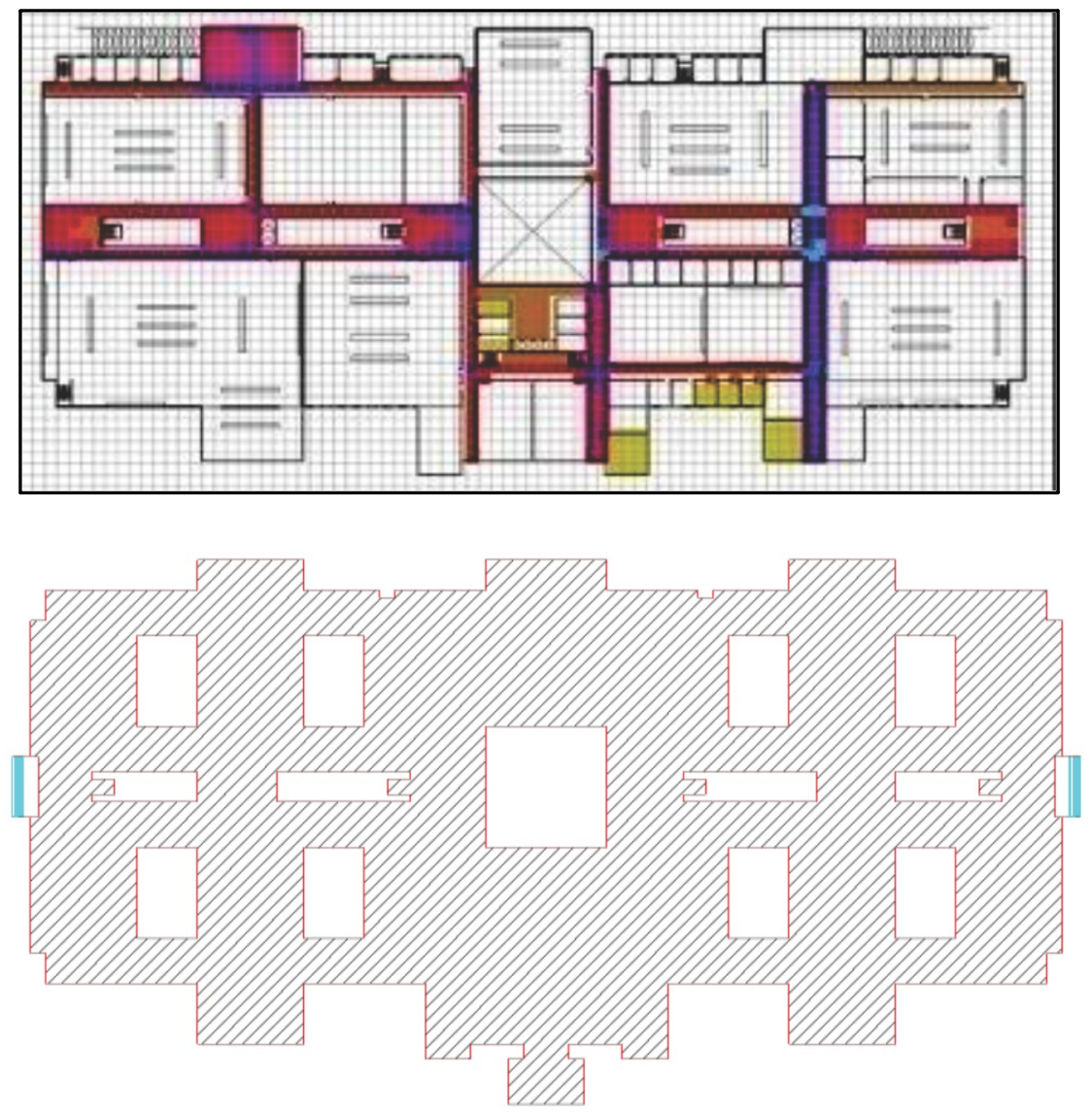

FIG. 7. MUDA WITH THE APPLICATION OF SPACE SYNTAX

Mehran University Research Journal of Engineering \& Technology, Volume 38, No. 3, July, 2019 [p-ISSN: 0254-7821, e-ISSN: 2413-7219] 
the provision of these pockets or open spaces, the building breath with air changes and these openings behave like lungs to the building and also help to control infections.

Fig. 8 depicts the typical floor plans of the FCP hospital building with axial lines depicting the circulation pattern and association between different spaces and their functions.

The axial lines on floor plan are drawn in red color. These axial lines are basically the connectivity lines to identify the walkability within the Hospital building.

The analysis of this hospital building shows that, it has a grid plan which is planning wise very efficient; whereas, the open to sky spaces does not affect negatively but positively to the hospital building and establish the efficiency of connectivity between natural environment and built environment. As a repercussion, healing environment become the outcome of the spatial organization in this hospital building [12].

The fourth step in the analysis of spatial organization of ICP is MURA with the application of Variation on the floor plans of the hospital building to assess the accessibility, functionality and barrier free circulation. The spaces are drawn with rectangular shapes whereas circulation is marked with arrows. These variation diagrams are basically drawn to show the schematic designs to solve the problem of the users concerning repetitiveness in their circulation pattern and increase their efficiency in the walkability and reduce the stress of staff and visitors within the Hospital building.

The Analysis of Spatial Organization in FCP Hospital
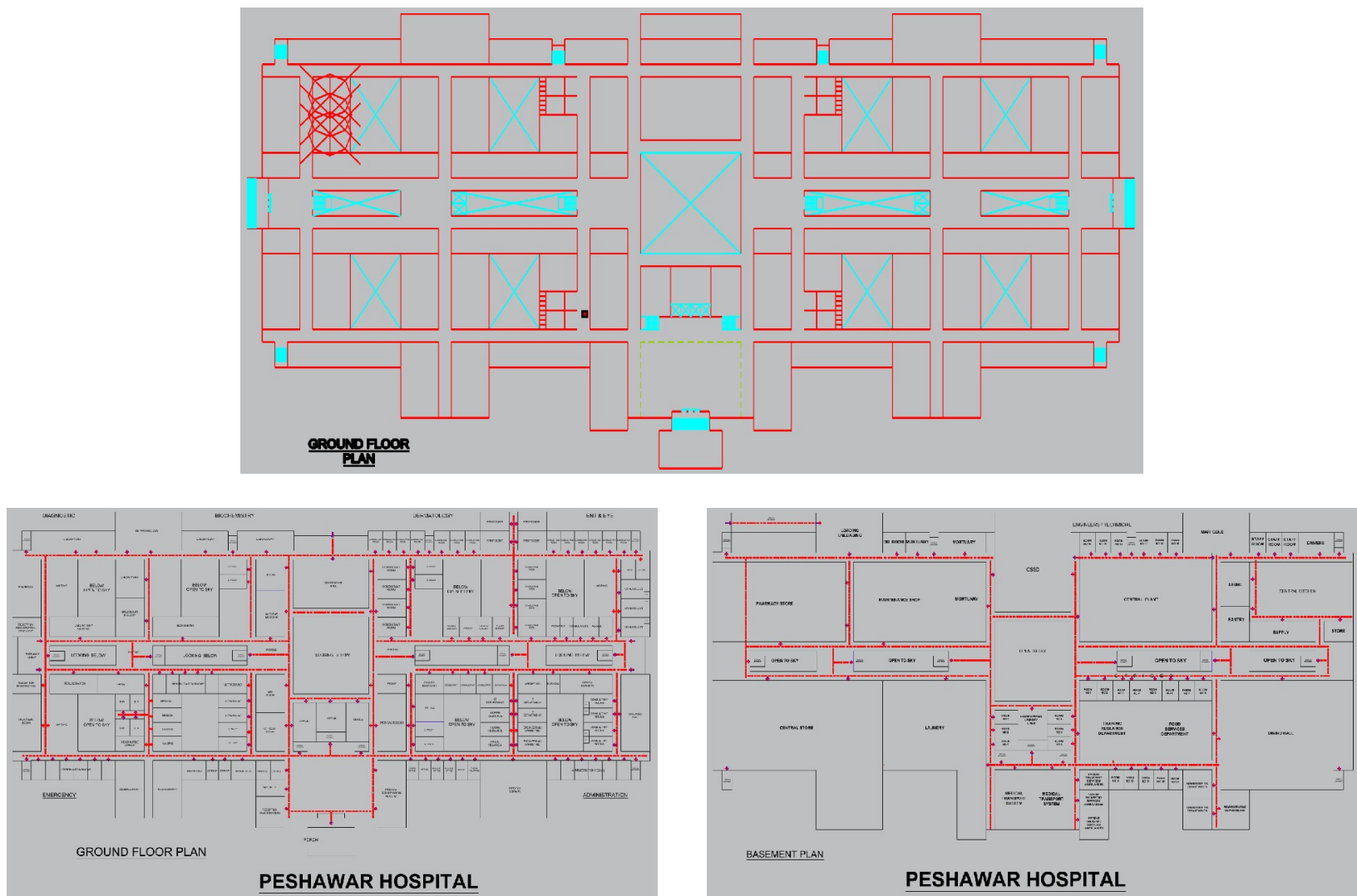

FIG. 8. MURI WITH APPLICATION OF AXIAL LINE

Mehran University Research Journal of Engineering \& Technology, Volume 38, No. 3, July, 2019 [p-ISSN: 0254-7821, e-ISSN: 2413-7219] 
Fig. 9 given below depicts the typical floor plans of the FCP hospital building with Variation diagram depicting the circulation pattern between various spaces of the hospital by daily users and visitors. The variation analysis of FCP hospital shows that the patient's rooms are appropriately aligned. The central spine is located where the staff, patients and visitors circulates. The most used spaces are placed near circulation and relatively less used spaces are away from the central spine. The work areas are well defined; the reception, conference and library lounge are located in one area which ensures accessibility and efficiency in the hospital building.

The fifth step in the analysis of spatial organization of ICP is to take the feedback and opinion of the concerned people and users of the hospital building. Table 2 portrays the tabulation of the opinion and replies of the interviewed respondents in the hospital.

The Analysis of Spatial Organization in FCP Hospital

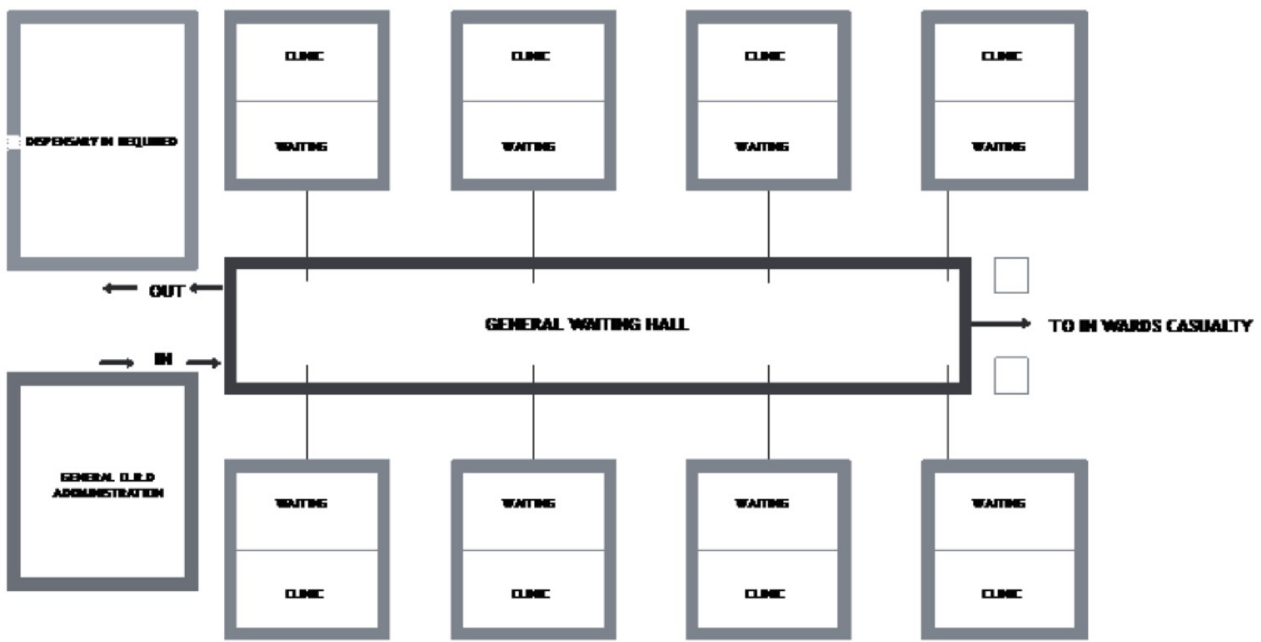

OUT PAIIEMT DEPARTMENT

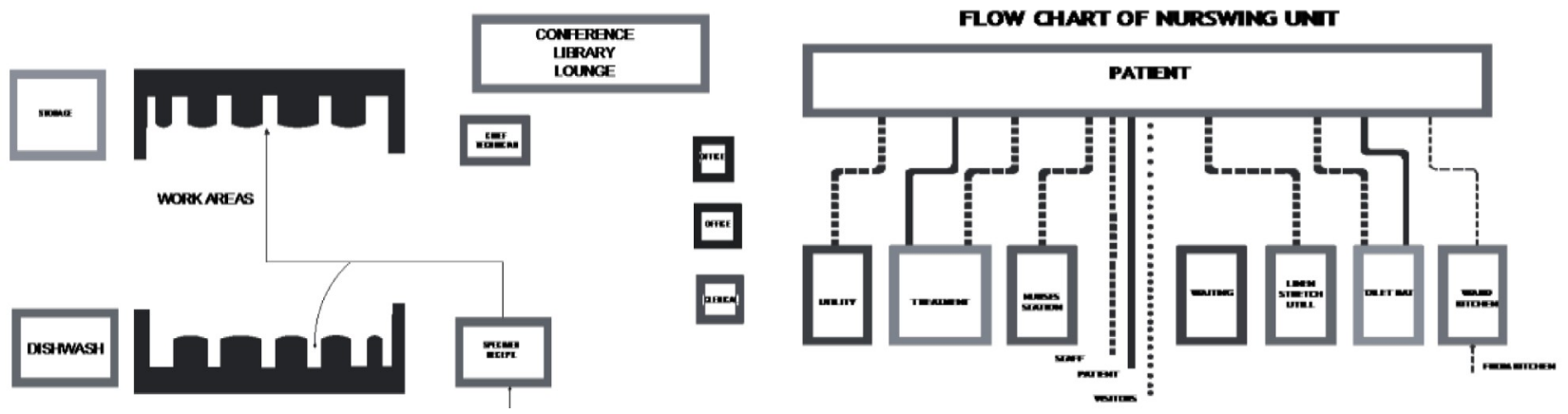

FIG. 9. MURA WITH THE APPLICATION OF VARIATION

TABLE 2. STATISTICAL ANALYSIS OF SPATIAL ORGANIZATION OF FCP

\begin{tabular}{|c|c|c|c|}
\hline \multirow{2}{*}{ FCP Hospital } & \multicolumn{3}{|c|}{ Spatial Organization } \\
\cline { 2 - 4 } & Muda & Mura & Muri \\
\hline Visibility Graph & 4 & 4 & 5 \\
\hline Space Syntax & 5 & 5 & 3 \\
\hline Axial Line & 3 & 4 & 4 \\
\hline
\end{tabular}

Mehran University Research Journal of Engineering \& Technology, Volume 38, No. 3, July, 2019 [p-ISSN: 0254-7821, e-ISSN: 2413-7219] 
Total 20 people were consulted and the earlier analysis on Muda, Mura and Muri was shared with them and their viewpoint was taken. The selection of respondents was fairly precise and categorized with the guidance of International Red Cross. These respondents contain nurses, doctors and architects of the hospital. A grading on the scale of 1 as best and 5 as worst was taken from them on all three variables therefore, Muda, Mura, Murias given in Table 2.

The feedback of respondents were taken on different issues i.e. schematic, designs, space division, functions, utilization, association and their use. In addition, circulation, accessibility, connectivity, barrier free movement, and walkability in the hospital were the other aspects of people's opinion survey. The analysis of spatial organization via interviews and their grading revealed that the hospital is very efficient in terms of design, circulation and connectivity for the movement of people and equipment Fig 10.

\subsubsection{Areal Distribution Analysis}

Areal distribution analysis is intended to study schematic design or bubble diagram of building to optimize the efficiency of hospital layout. The areal distribution analysis provides optimal suggestions and suitable solution to the problem around the triage system. Depth map and space syntax are contemporary areal distribution analysis methods and tools for understanding and investigating connections in hospital building to access healing outcomes. The suitable hospital building shapes are discussed in this analysis. There are two case studies conducted under this analysis and each one explores the architectural design policyapplications and its feasibility is the focus of analysis.

\subsubsection{Synthesis of analysis}

Conclusively, the $3 \mathrm{M}$ analyses has been done to identify the perfect healing environment, aerial distribution and adequate spatial organization with the application of Kaizen theory (Fig. 11).

When given two variables $\mathrm{x}$ and $\mathrm{y}$, if $\mathrm{y}$ is directly proportional to $\mathrm{x}$, the relation is represented as, the $\alpha$ the constant ratio, where Mura is directly proportionate to sort and straight, Muri is directly proportionate to Standardization and Muda is inversely proportionate to shine (Fig. 12).

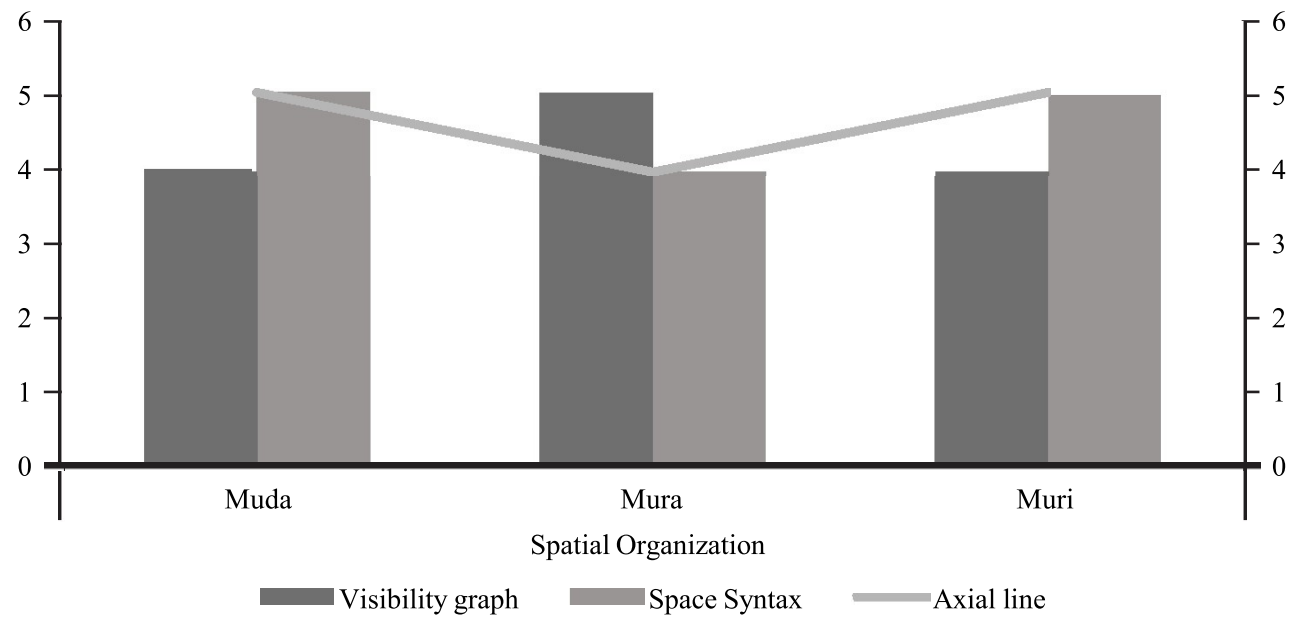

FIG. 10. STATISTICAL ANALYSIS OF SPATIAL ORGANIZATION IN FCP HOSPITAL WITH THE APPLICATION OF VISIBILITY GRAPH, SPACE SYNTAX AND AXIAL LINE

Mehran University Research Journal of Engineering \& Technology, Volume 38, No. 3, July, 2019 [p-ISSN: 0254-7821, e-ISSN: 2413-7219] 


\section{RESULTS AND DISCUSSION}

The healthcare facility environments have both positive and negative impacts on patients. Therefore, spatial arrangement and areal distribution must respond to the healing needs of users. Thus, this research intends to improve Healing Environment within acute care hospital buildings in Pakistan based on Design Determinants, Spatial Organization, and Areal Distribution. The introduction is based on the attempt to visualize and analyze the status of healing environment in acute care hospital buildings within Pakistan so as to improve them. A variety of tools are explored in this regard to evaluate the case studies conducted in Pakistan to maximize the achievement of healing environment.

The analysis of spatial organization of ICP through respondent's interviews and grading portrays that it has $45 \%$ less wastage spaces based on circulation pattern in the hospital, accessibility, connectivity and barrier free movement within buildings, walkability status of over stressed staff within the Hospital building, functionality of the schematic designs and the problem of the users concerning repetitiveness in their circulation pattern as well as the way to increase the efficiency of spaces, their spread and flow in the hospital building obtained through feedback of concerned people on design determinants.

There is a continuous traffic through the lobby which is moderate to heavy depending during the time of the day

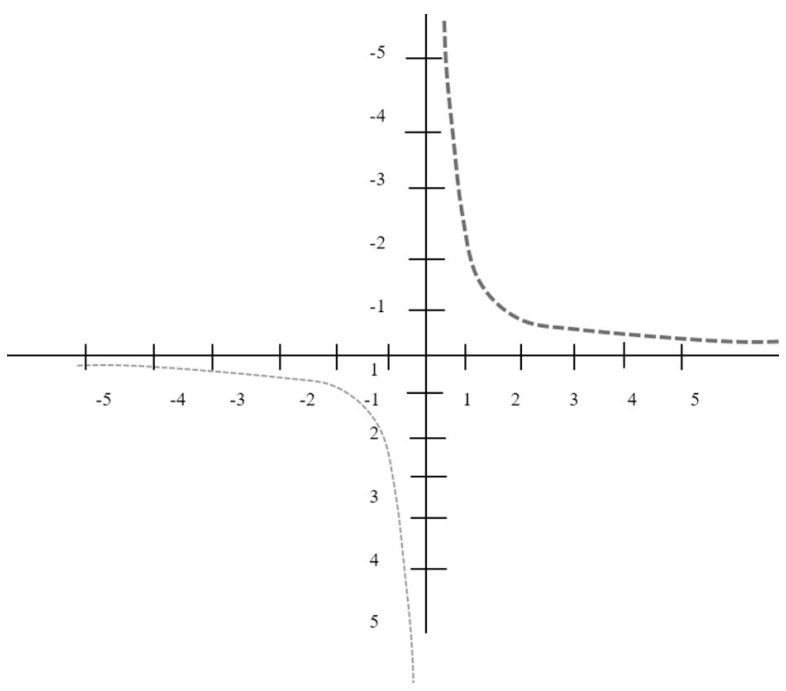

FIG. 12. INVERSE PROPORTIONALITY WITH A FUNCTION OF $Y=1 / X$

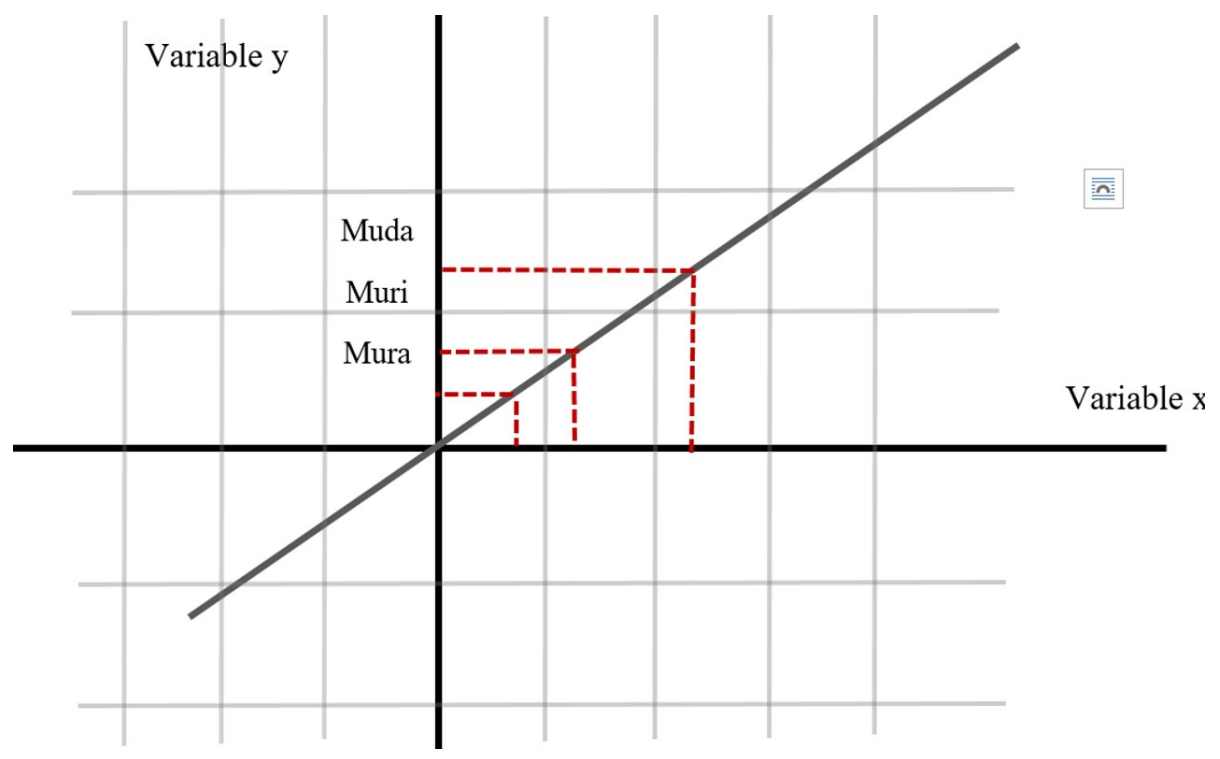

FIG. 11. SYNTHESIS OF ANALYSIS, DIRECTLY PROPORTIONAL

Mehran University Research Journal of Engineering \& Technology, Volume 38, No. 3, July, 2019 [p-ISSN: 0254-7821, e-ISSN: 2413-7219] 
and the day of the week made up of outpatient, inpatient and admitting patients, usually accompanied by relatives and visitors. These often move in small groups, such traffic consisting of patients on crutches, in wheel chairs and some on stretchers.

(i)

To let the circulation move smoothly. Circulation should be planned efficiently in terms of navigation.

(ii)

Circulation areas should be generous- not less than one third of the waiting area.

(iii)

The design of the outpatient department must consider maximum utilization of space, equipment and personnel, control of patients, personnel and support traffic is imperative.

In principle, there should be the following four separate entrances to a hospital. The first is the main hospital entrance. The second is the outpatient entrance. The third and forth are the emergency entrance and service entrance respectively. A great deal of thought should be given to planning for the development of traffic flow for patients, personnel and visitors within the building and between the departments. The objective is to expedite traffic, eliminate congestion and promote efficiency of operation on separating public corridors from patient corridors and staff corridors as far as possible. Hospital should be designed in such a way that the staff, patients and visitors can easily orient themselves within the building. The nurses' station should be located on a point where nurses exercise the control over patients' corridor and the visitors entrance.

A great deal of thought should be given to planning for the development of traffic flow for patients, personnel and visitors within the building and within and between the departments. The objective is to expedite traffic, eliminate congestion and promote efficiency of operation on separating public corridors from patient corridors and staff corridors as far as possible. Hospital should be designed in such a way that the staff, patients and visitors can easily orient themselves within the building. The nurses' station should be located on a point where nurse exercise the control over patients' corridor and the visitors entrance.

Fig. 13 indicates the relationship of corridor and barrier free which is denoted by plus $(+)$ meaning positive relationship. The space could be utilized maximum by applying Muda here as it is concluded that Muda is directly proportionate to visibility: i.e. Muda $\alpha$ Visibility. According to the table corridor and Egress has (- -) highly negative relationship since egress is located at the entry point. Though Barrier free and egress has highly positive relationship denoted by $(++)$.

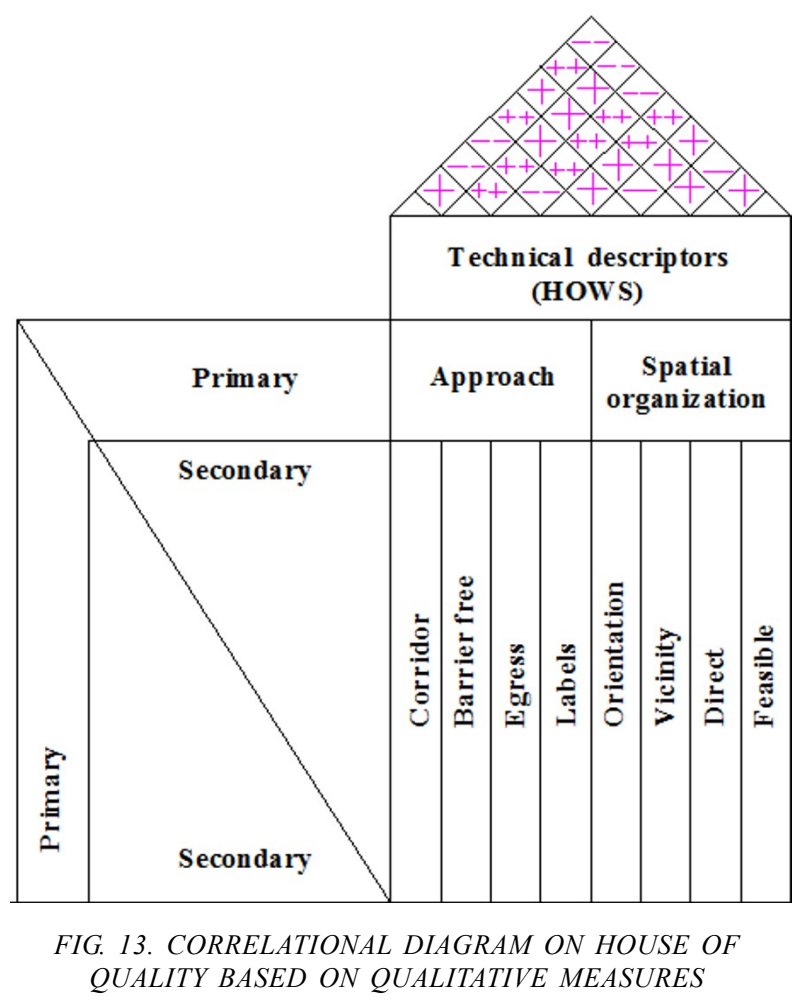

Mehran University Research Journal of Engineering \& Technology, Volume 38, No. 3, July, 2019 [p-ISSN: 0254-7821, e-ISSN: 2413-7219] 
The purpose of this research is to study the existing facility available and to re-plan the entire hospital. The functional program would list the facilities and determine the space required for every facility. The requirements should also indicate the relationship that should pertain between the various hospital departments e.g. whether the emergency should be located near the surgical unit, near the diagnostic radiology, or near the clinical laboratory. Therefore, removing Muri will help as it is the variation and confusion in the building type.

Intensive literature review suggested that efficiency in terms of spatial organization in a hospital design can be improved by the use of lean six sigma which is a continuous improvement where Muda, Muri and Mura implies wastage in terms of space which can be reduced by applying space syntax application on depth map i.e. axial line, connectivity and visibility graph this will remove the wastage in space (Mura), and unevenness due to an array of variation found in the planning. Moreover (Muri) describes over exhausted people: this can be achieved by simulation of the hospital plan on space syntax where unused spaces can be eradicated while the axial lines on the plan describes the visual connectivity and approach from one point in the hospital to the other.

\subsection{Algorithm for Eliminating Wastage}

As shown in Fig. 13, vicinity and direct are directly proportionate. It can also be denoted as Vicinity $\alpha$ Orientation since maximum visibility shows minimum stress. Also, Mura is inversely proportionate to Axial Line, i.e. Mura $\alpha$ Axial Line ${ }^{-1}$. This is represented by orientation and corridor which shows $(++)$ relationship that is highly positive.
Whereas Muri $\alpha 1 /$ Space Syntax, which infers standardize aids circulation and variation confused staff and visitors. FC hospital is open to sky and is using space to maximum efficiency while it is planned on grid. Label and orientation are positively related as studied at both the hospital in Peshawar.

\section{CONCLUSION}

This research was a comprehensive analysis of healthcare facilities in Pakistan in relation to healing environment improvement of spatial organization, areal distribution and design determinants with the aim of improvements. The research aimed to remove all sorts of wastage of space in hospital and variation of space. Mura, Muda and Muri concept was applied in this study; Mura (Wastage of physical strength of people) is removed by axial lines which are created in space syntax and Muri (Variation in spaces) is tackled with maximization of connectivity and Muda (wastage of space) is dealt with through visibility graph in space syntax. Thus it was proved conclusively that the wastage could be removed up to $40 \%$ by application of the set tools.In conclusions/recommendations, we state that future work should focus more on indoor navigational techniques.

\section{ACKNOWLEDGEMENT}

The authors would like to thank University of Arts \& Culture, and Mehran University of Engineering \& Technology, Jamshoro, Pakistan, for facilitating this research.

\section{REFERENCES}

[1] Akram, M., and Khan, F.J., "Health Care Services and Government Spending in Pakistan, Islamabad: Pakistan Institute of Development Economics, 2007..

Mehran University Research Journal of Engineering \& Technology, Volume 38, No. 3, July, 2019 [p-ISSN: 0254-7821, e-ISSN: 2413-7219] 
[2] Mourshed, M., and Zhao, Y., "Healthcare Providers' Perception of Design Factors Related to Physical Environments in Hospitals", Journal of Environmental Psychology, Volume 32, No. 4, pp. 362-370, 2012.

Vinod, M., Devadasan, S.R., Sunil, D.T., and Thilak, V.M.M., "Six Sigma through Poka-Yoke: A Navigation through Literature Arena", The International Journal of Advanced Manufacturing Technology, Volume 81, No. 1-4, pp. 315-327, 2015.

Gill, J., "Quality Follows Quality: Add Quality to the Business and Quality will Multiply the Profits", The TQM Journal, Volume 21, No. 5, pp. 530-539, 2009.

Shaikh, J., "A Study of the User Friendly Navigation for Health Care Facility in Pakistan, Based on Design Determinents”, Ph.D., Dissertation, Hanyang University, Korea, 2017.

Martin, E., Oriol, V., Gerald, F., and Ruzena, B., "Precise Indoor Localization Using Smart Phones", Proceedings of 18th ACM International Conference on Multimedia, pp. 787-790, 2010.

Zlatanova, S., Liu, L., George, S., Junqiao, Z., and Filippo, M., "Space Subdivision for Indoor Applications", Delft University of Technology, OTB Research Institute for the Built Environment, 2014.
[11] Krûminaitë, M., and Zlatanova, S., "Indoor Space Subdivision for Indoor Navigation", Proceedings of $6^{\text {th }}$ ACM SIGSPATIAL International Workshop on Indoor Spatial Awareness, pp. 25-31, 2014.

[12] Liu, L., and Zlatanova, S., "Towards a 3D Network Model for Indoor Navigation”, Urban and Regional Data Management, UDMS Annual, pp. 79-92, 2011.

Dogu, U., and Feyzan, E., "Spatial Factors Affecting Wayfinding and Orientation: A Case Study in a Shopping Mall”, Environment and Behavior, Volume 32, No. 6, pp. 731-755, 2000.

[14] Dill, D., "Academic Planning and Organizational Design: Lessons from Leading American Universities", Higher Education Quarterly, Volume 50, No. 1, pp. 35-53, 1996.

[15] Vischer, J., "Post-Occupancy Evaluation: A Multifaceted Tool for Building Improvement”, Learning from Out Buildings: A State-of-the-Practice Summary of PostOccupancy Evaluation, pp. 23-34, 2002.

[16] Ohno, T., "Toyota Production System: Beyond LargeScale Production", CRC Press, 1988.

[17] Ohno, T., "How the Toyota Production System was Created", Japanese Economic Studies, Volume 10, No. 4, pp. 83-101, 1982.

[18] Hampton, T., "Hospitals and Clinics Go Green for Health of Patients and Environment", JAMA, Volume 298, No. 14, pp. 1623-1629, 2007

[19] Cheng, L.P., and Tang, N.K., "The Development of a Model for Total Quality Healthcare", Managing Service Quality: An International Journal, Volume 10, No. 2, pp. 103-111, 2000. Healthcare: The Unfilled Promise?", Social Science \& Medicine, Volume 74, No. 3, pp. 364-371, 2012. 
[21] Sakallaris, B.R., Macallister, L., Voss, M., Smith, K., and Jonas, W.B., "Optimal Healing Environments", Global Advances in Health and Medicine, Volume 4, No. 3, pp. 40-45, 2010.

[22] Frumkin, H., "Healthy Places: Exploring the Evidence", American Journal of Public Health,Volume 93, No. 9, pp. 1451-1456, 2003.

[23] Beauchemin, K.M., and Hays, P., "Sunny Hospital Rooms Expedite Recovery from Severe and Refractory Depressions", Journal of Affective Disorders, Volume 40, No. 1, pp. 49-51, 1996.
[24] Heerwagen, J.H., and Orians, G.H., "Adaptations to Windowlessness: A Study of the Use of Visual Decor in Windowed and Windowless Offices", Environment and Behavior,Volume 18, No. 5, pp. 623-639, 1986.

[25] Ulrich, R.S., "Effects of Interior Design on Wellness: Theory and Recent Scientific Research", Journal of Health Care Interior Design, Volume 3, No. 1, pp. 97-109, 1991.

[26] Forman, A.D., "Healing by Design", The New England Journal of Medicine, Volume 334, No. 5, pp. 334-5, 1996. 